\title{
LEITURA E INTERPRETAÇÃO DE ARTIGOS CIENTÍFICOS POR ALUNOS DE GRADUAÇÃO EM QUÍMICA
}

\section{Reading and interpretation of scientific articles by undergraduate chemistry students}

\author{
Gelson Ribeiro dos Santos ${ }^{1}$ \\ Salete Linhares Queiroz ${ }^{2}$
}

\begin{abstract}
Resumo: Este trabalho descreve o uso de artigos científicos em um curso de Comunicação Científica oferecido a alunos de graduação em Química. O principal objetivo da atividade foi desenvolver as habilidades de leitura e interpretação deste tipo de texto por parte dos alunos. A atividade proporcionou aos mesmos a expressão de uma grande quantidade de idéias, resultantes das suas reflexões sobre os conteúdos presentes nos artigos, e foi analisada com base na Análise de Discurso, na linha francesa.

Palavras-chave: Ensino superior. Química. Análise de discurso.

Abstract: This work describes the use of scientific articles in a scientific communication course for undergraduate chemistry students. The main goal was to develop students' interpretative abilities of this kind of material. The activity was analyzed based on French Discourse Analysis. It was concluded that the assignment enabled the students to express a great number of ideas resulting from their reflection on the texts.
\end{abstract}

Key words: Graduate education. Chemistry. Discourse analysis.

\footnotetext{
${ }^{1}$ Mestre em Química; professor de Química, rede pública de ensino do Estado de São Paulo. São Carlos, SP. <gelson@iqsc.usp.br>

${ }^{2}$ Doutora em Química; professora, Instituto de Química de São Carlos, Universidade de São Paulo. São Carlos, SP. <salete@iqsc.usp.br>

${ }^{1}$ Avenida Trabalhador São-carlense, 400

São Carlos, SP

13.560-970

193

Ciência ङ̊ Educação, v. 13, n. 2, p. 193-209, 2007
} 
Santos, G. R.; Queiroz, S. L.

\section{Introdução}

Nos últimos anos, tem-se verificado uma crescente preocupação, por parte de educadores que se dedicam ao Ensino Superior de Química, em relação à necessidade de adoção de estratégias/ações que privilegiem o papel do aluno no processo de ensino-aprendizagem desta disciplina (ZANON, ALMEIDA e QUEIROZ, 2007). Tais preocupações orientam a construção e a concretização de propostas curriculares no mundo inteiro que enfatizam a importância do oferecimento de uma formação mais geral aos graduandos e a relevância do estímulo ao desenvolvimento de um caráter crítico-reflexivo dos mesmos (COPOLLA, EGE e LAWTON, 1997). No Brasil, as Diretrizes Curriculares para os Cursos de Química (ZUCCO, PESSINE e ANDRADE, 1999) apontam nesta direção, quando afirmam que "os currículos vigentes estão transbordando de conteúdos informativos em flagrante prejuízo aos formativos, fazendo com que o estudante saia do curso de graduação com 'conhecimentos' já desatualizados e não suficientes para uma ação interativa e responsável na sociedade, seja como profissional, seja como cidadão"; e quando destacam habilidades desejadas do profissional da área, que ultrapassam o domínio cognitivo dos conteúdos e abarcam aspectos como: o reconhecimento da química como uma construção humana; a leitura, compreensão e interpretação de textos científico-tecnológicos em idioma pátrio e estrangeiro; a comunicação de resultados de pesquisa em linguagem científica oral e escrita; a identificação e realização de buscas nas fontes de informações relevantes para a Química.

Neste contexto, temos como objetivo, no presente trabalho, descrever uma proposta de ensino que busca favorecer o desenvolvimento de algumas das habilidades anteriormente citadas, especialmente a leitura, compreensão e interpretação de textos científico-tecnológicos por parte dos graduandos. Acreditamos que o desenvolvimento de tais habilidades os auxilia na realização de suas atividades de iniciação científica (QUEIROZ e ALMEIDA, 2004) e no desempenho futuro de tarefas como profissionais da área, embora seja pequena a atenção a elas dispensada durante o curso universitário (WHELAN e ZARE, 2003; QUEIROZ, 2001).

A proposta, baseada na utilização de artigos científicos, foi aplicada na disciplina Comunicação e Expressão em Linguagem Científica II, oferecida para alunos matriculados no segundo semestre do curso de Bacharelado em Química do Instituto de Química de São Carlos, Universidade de São Paulo. A análise dos dados obtidos foi realizada tendo em vista, notadamente, a discussão do seu potencial no desenvolvimento das referidas habilidades. Para tanto, buscamos subsídios em alguns pressupostos da Análise de Discurso, na linha francesa e, sobretudo, na noção de autoria, na perspectiva divulgada por Orlandi (2002).

\section{Metodologia}

Foram tomados como sujeitos da pesquisa 55 alunos matriculados na disciplina anteriormente mencionada. Para que a proposta de ensino fosse colocada em funcionamento, fezse necessária, inicialmente, a seleção dos artigos científicos que seriam distribuídos aos alunos e a definição da maneira como deveriam proceder com a leitura e a discussão dos artigos. Foram selecionados artigos publicados em língua portuguesa, com o número médio de cinco 
páginas, apresentando conteúdos compatíveis com conhecimentos adquiridos pelos alunos até a conclusão do primeiro semestre do curso de graduação em Química. No que diz respeito à maneira como os alunos deveriam proceder com a leitura dos artigos, foram oferecidas questões, que deveriam ser solucionadas em grupo. Os critérios para a escolha dos artigos e para a elaboração das questões foram estabelecidos tomando-se por base algumas considerações reportadas na literatura (SANTOS, SÁ e QUEIROZ, 2006), que indicam a preferência dos alunos pela leitura de artigos que não são demasiadamente extensos e que privilegiam a reflexão e a discussão sobre aspectos não apenas científicos, mas também tecnológicos e sociais.

No primeiro dia de aula, os alunos foram informados que as atividades do primeiro bimestre envolveriam a leitura e a discussão de artigos científicos, a preparação de uma apresentação oral, de um painel e de um texto sobre o conteúdo dos mesmos. Nessa ocasião, foram formados 15 grupos, constituídos de, aproximadamente, 4 alunos. Artigos científicos extraídos das revistas Química Nova e Eclética Química foram distribuídos aleatoriamente entre os grupos. Cada grupo recebeu um artigo.

Um total de oito horas-aula (duas horas-aula por semana, durante quatro semanas) foi dedicado às atividades de leitura e discussão dos artigos científicos. Nos três primeiros dias de atividade, os alunos assistiram a uma aula expositiva ministrada pelo docente responsável pela disciplina sobre a elaboração das apresentações orais e de painéis, e discutiram aspectos relacionados ao conteúdo e ao processo de produção do artigo científico, solucionando as questões apresentadas no Quadro 1.

Algumas questões também foram solucionadas pelos alunos fora do período normal de aula e encontram-se ilustradas no Quadro 2. No quarto dia de atividades, concluída a etapa de leitura e discussão das questões, as respostas fornecidas pelos alunos foram reunidas pelo professor e debatidas em sala de aula. Essa atividade visou confrontar idéias que os alunos demonstraram acerca da forma pela qual o conhecimento científico apresentado em um artigo científico é gerado com aspectos reais da produção deste conhecimento.

$\mathrm{Na}$ penúltima semana do bimestre, os alunos fizeram as apresentações de painéis relacionados aos conteúdos dos artigos com os quais haviam trabalhado, em um intervalo de duas horas. $\mathrm{Na}$ última semana, foi organizado um mini-simpósio, durante um intervalo de quatro dias, sendo duas horas por dia reservadas para cada sessão, totalizando, aproximadamente, sete horas e meia de duração. Nesse mini-simpósio o conteúdo do artigo científico estudado foi apresentado por um dos membros de cada grupo, em um intervalo de 15 a 20 minutos. A programação do mini-simpósio foi elaborada de tal forma que quatro artigos diferentes foram apresentados nas três primeiras sessões e três artigos na última sessão. Além do professor responsável pela disciplina, quatro outros docentes do Instituto de Química de São Carlos (um docente por sessão) assistiram e avaliaram as apresentações orais dos alunos. Embora todos os alunos tenham sido convidados a assistir a todas as apresentações do minisimpósio, tiveram de comparecer, obrigatoriamente, apenas àquelas apresentações programadas para o mesmo período reservado para o seu grupo. Assim, os alunos dedicaram aproximadamente dez horas para as atividades realizadas em sala de aula. Porém, acreditamos que um tempo considerável tenha sido utilizado por eles em atividades extraclasse, que envolveram: buscas por informações para resolução das tarefas extraclasse, preparação dos painéis e preparação das apresentações orais. 
Santos, G. R.; Queiroz, S. L.

\section{A - Fazendo o reconhecimento do artigo}

1. Título do artigo; 2. Autores do artigo; 3. Instituições a que pertencem os autores do trabalho; 4. Cite a(s)

agência(s) que forneceu(ram) auxílio financeiro ao trabalho.

\section{B - Pensando sobre suas respostas}

1. Qual critério foi escolhido por vocês para indicar o autor principal do artigo? O que faz com que ele ocupe esta posição?; 2 . Se o trabalho desenvolvido neste artigo foi realizado através da interação de diferentes universidades e/ou institutos de pesquisa, por que vocês imaginam que estas interações são necessárias?; 3. Vocês conhecem a(s) agência(s) de fomento citada(s) neste artigo? Como vocês imaginam que essas agências distribuem suas verbas para os pesquisadores?

\section{C - Colocando a mão na massa I}

1. Todos os membros do grupo devem fazer a leitura do título do artigo. Um dos membros se responsabiliza por coordenar um brainstorming. Este membro deve fazer anotações sobre os resultados obtidos com este procedimento; 2. Cada um dos membros do grupo faz a leitura da introdução do artigo e sublinha todas as palavras cujo significado não é conhecido. O membro do grupo que coordenou o brainstorming deve anotar todas as palavras/expressões assinaladas por todos os outros colegas. Discutir as palavras grifadas e, por meio de troca de informações entre os membros, tentar compreender o significado das mesmas. 3. Repitam o procedimento adotado na resolução da questão anterior, lendo agora a parte sobre materiais e métodos do artigo; 4. Quais foram as substâncias químicas utilizadas no trabalho? Por que estas substâncias foram escolhidas?; 5. Quais foram os materiais e técnicas químicas mencionados no artigo? Selecionem os materiais que vocês já conhecem e expliquem as suas funções e, no caso das técnicas, expliquem os seus princípios.

\section{D - Colocando a mão na massa II}

1. Cada um dos membros do grupo faz a leitura das seções finais do artigo e sublinha todas as palavras cujo significado não é conhecido. O membro do grupo que coordenou o brainstorming deve anotar todas as palavras/expressões assinaladas por todos os outros colegas. Discutir as palavras grifadas e, por meio de troca de informações entre os membros, tentar compreender o significado das mesmas 2. Na opinião de vocês, qual(is) o(s) principal(is) problema(s) que os autores do artigo se propuseram a solucionar?; 3. Como você(s) acredita $(\mathrm{m})$ que os pesquisadores, em geral, escolhem os seus problemas de pesquisa? 4. Os autores solucionaram o(s) problema(s) com os quais haviam se deparado inicialmente? Justifiquem as suas respostas, apresentando fatores decisivos que contribuíram para esta solução (ou não) do(s) problema(s) 5. Agora que vocês concluíram a leitura do artigo, apresentem as habilidades que vocês acreditam que foram utilizadas pelos autores desde o início da pesquisa até a sua publicação. Coloquem-se no papel de um dos autores e produzam um texto (no gênero que vocês acharem melhor) que mostre situações em que vocês (lembrem-se, no papel do autor!) fazem uso destas habilidades.

Quadro 1. Questões sobre aspectos relacionados ao conteúdo e ao processo de produção do artigo científico solucionadas pelos alunos em sala de aula. 
Leitura e interpretação de artigos científicos...

\section{Atividades Extraclasse I}

1. Apresentem uma breve descrição das técnicas empregadas no artigo; 2. Mostrem as estruturas e algumas propriedades das principais substâncias químicas utilizadas no artigo e relatem a função de cada uma delas neste trabalho; 3 . Apresentem os significados das palavras que vocês grifaram durante o trabalho realizado em sala; 4. Utilizando recursos de buscas de artigos científicos já conhecidos por vocês (Web of Science, Chemical Abstracts e Currículo Lattes), localizem trabalhos relacionados ao artigo que vocês têm em mãos, que tenham sido publicados pelos autores. Façam cópias e anexem à folha de respostas, pelo menos, dois dos artigos localizados.

\section{Atividades Extraclasse II}

1. Apresentem os significados das palavras que vocês grifaram durante o trabalho realizado em sala; 2 . Utilizando recursos de buscas de artigos científicos já conhecidos por vocês (Web of Science, Chemical Abstracts e Currículo Lattes), localizem trabalhos relacionados ao assunto tratado no artigo que vocês têm em mãos. Façam cópias e anexem à folha de respostas, pelo menos, dois dos artigos localizados. Justifiquem a escolha dos artigos, ou seja, no que eles se assemelham ao artigo trabalhado em sala; 3 . Apresentem uma análise dos principais gráficos, tabelas e figuras existentes no artigo; 4 . Com base na leitura do artigo e daqueles a ele relacionados (buscas realizadas extraclasse), considerem: a) qual a importância da pesquisa para a sociedade; b) quais são as suas possíveis aplicações; c) citem outras abordagens dadas ao assunto tratado no artigo por outros pesquisadores. Façam comentários sobre essas abordagens, comparando-as com aquela utilizada pelo autor do texto utilizado em sala; 5 . As referências bibliográficas citadas no artigo sustentam as informações contidas nele? De que forma?

Quadro 2. Questões sobre aspectos relacionados ao conteúdo e ao processo de produção do artigo científico solucionadas pelos alunos fora da sala de aula (atividades extraclasse).

Concluídas todas as aulas previstas, os alunos produziram, individualmente, um texto (gênero livre), que deveria versar sobre o conteúdo do artigo científico, dirigido a um leitor com as características de um calouro do curso de Bacharelado em Química. O texto deveria destacar os fundamentos, objetivos e relevância da pesquisa descrita no artigo.

A coleta de dados foi feita por meio dos seguintes procedimentos:

. solicitação de respostas escritas a questões apresentadas no Quadro 1 e no Quadro 2;

. solicitação da produção de um painel;

- filmagem em fitas VHS das aulas nas quais os conteúdos dos artigos científicos foram apresentados;

. solicitação da produção de um texto, de gênero livre, que versasse sobre o conteúdo do artigo científico.

Cabe esclarecer que nem todos os dados coletados serão aqui discutidos. Neste trabalho analisamos cinco textos, visando discutir o potencial da proposta para o desenvolvimento da habilidade de leitura e interpretação de artigos científicos dos alunos. 


\section{Fundamentos teóricos}

Ao iniciar as discussões sobre o objeto teórico da Análise de Discurso (AD), Orlandi (2002) a caracteriza como uma disciplina que, conforme o seu próprio nome indica, não trata da língua e nemda gramática. Trata do discurso. Este é produzido socialmente por meio de sua materialidade específica (a língua), e pode ser apreendido com base na análise dos processos de sua produção. E a palavra discurso tem em si a idéia de curso, de percurso, de movimento. "O discurso é, assim, palavra em movimento, prática de linguagem: com o estudo do discurso observa-se o homem falando" (ORLANDI, 2002, p. 15). O trabalho com o discurso implica a construção de sentidos com base nas condições de produção do mesmo.

Da observação da linguagem em seu contexto, e em termos bastante gerais, Orlandi (1996) propõe que a produção do discurso se faz na articulação de dois grandes processos, que seriam o fundamento da linguagem: o processo parafrástico e o processo polissêmico. O processo parafrástico é o que permite a produção do mesmo sentido sob várias de suas formas (matriz da linguagem), e o processo polissêmico é o responsável pelo fato de que são sempre possíveis sentidos diferentes, múltiplos (fonte de linguagem). Assim, de um lado, há um retorno constante a um mesmo dizer sedimentado, a reprodução, o clichê - a paráfrase - e, de outro lado, há, no texto, uma tensão que aponta para o rompimento, dispõe-se da multiplicidade, do diferente. A polissemia é essa força na linguagem que desloca o mesmo, tensão entre o texto e o contexto histórico-social; o conflito entre o "mesmo" e o "diferente" (ORLANDI, 1996).

De particular interesse para a análise dos dados obtidos nesta pesquisa é o conhecimento, na abordagem da AD, da idéia de autoria. Compreender autoria supõe compreender os procedimentos que autores, pessoas físicas, lançam mão ao compor seus discursos. Por isso é que o autor pode ser entendido como princípio que confere ao discurso unidade (FOUCAULT, 2004).

A autoria, na visão de Orlandi (1996), representa a função que se realiza toda vez que o produtor da linguagem se encontra produzindo um texto com unidade, coerência, progressão, não-contradição e fim. O autor responde pelo que diz ou escreve, pois supostamente está na sua origem, embora se constitua pela repetição, pelo interdiscurso, ele historiciza seu dizer: é na escrita que se tem a autoria testada, por ser uma forma material da relação com o simbólico. Dessa forma, a autora distingue: repetição empirica, repetição formal e repetição bistórica.

A repetição empírica refere-se ao exercício mnemônico, em que o indivíduo repete exatamente da forma como leu ou ouviu. A repetição formal trata do exercício gramatical, em que o indivíduo repete o que leu ou ouviu de maneira um pouco diferenciada, muda as frases, isto é, diz a mesma coisa com palavras diferentes. E, na repetição histórica, ocorre a interpretação, pois o repetível, aqui, faz parte da memória constitutiva do sujeito, ele consegue formular e constituir seu enunciado no interior das repetições.

Orlandi (2000) coloca a noção de autoria para uso corrente, como sendo uma função que a escola deva se preocupar em desenvolver. Para ela, a posição-autor se faz na constituição da interpretação, pois o autor não pode dizer coisas que não tenham sentido, o que mostra sua relação com o interdiscurso e, além de fazer sentido, este deve ser dirigido a um interlocutor determinado, que faz parte de suas formações imaginárias. A interpretação, pois, não seria apreender, mas atribuir sentidos, mesmo porque eles não existem a priori.

As noções de formação discursiva, interdiscurso e formação imaginária também fo- 
ram fundamentais para a análise dos dados obtidos. Para a AD, os sentidos não existem em si, mas são determinados pelas posições ideológicas colocadas em jogo no processo em que as palavras são produzidas. Orlandi (2002) trata as formações discursivas como aquilo que, a partir de uma posição dada em uma determinada conjuntura sociohistórica, pode e deve ser dito. De acordo com esta concepção, as palavras mudam de sentido segundo as posições daqueles que as empregam. Elas "tiram" seu sentido dessas posições, isto é, em relação às formações nas quais essas posições se inscrevem. A formação discursiva caracteriza-se, então, como uma "matriz" do sentido: ela "dita as regras" para o que o sujeito pode e deve dizer no âmbito de suas práticas sociais e, até mesmo, para aquilo que não pode e não deve ser dito.

A noção de interdiscurso pode ser relacionada com a noção de formação discursiva no que diz respeito ao aparecimento do "já dito". Orlandi (2002) trata o interdiscurso como memória discursiva: o interdiscurso disponibiliza dizeres, determinando, pelo "já dito", aquilo que constitui uma formação discursiva em relação a outra. O interdiscurso compõe o conjunto de todos os sentidos já ditos por alguém, em algum lugar, em outros momentos, e que determinam o que dizemos. Exemplificando: "para que minhas palavras tenham sentido é preciso que elas já façam sentido" (ORLANDI, 2002, p. 33). A autora ainda esclarece que é necessário não confundir o interdiscurso com a intertextualidade. O interdiscurso está relacionado com o saber discursivo, memória afetada pelo esquecimento ao longo do dizer, enquanto o intertexto restringe-se à relação de um texto com outros textos.

No que diz respeito às formações imaginárias, estas podem se manifestar pela antecipação das relações de força e de sentidos. Assim, todo processo discursivo supõe a existência dessas formações. Segundo esta noção, os sentidos resultam destas relações: um discurso aponta para outros que o sustentam, assim como para dizeres futuros (ORLANDI, 2002). Por antecipação, o sujeito projeta uma representação imaginária do seu interlocutor e, a partir dela, estabelece suas estratégias discursivas. Pela relação de forças, Orlandi (2002, p. 39) ressalta que o lugar a partir do qual fala o sujeito é constitutivo do que ele diz. Assim, "se o sujeito fala a partir do lugar do professor, suas palavras significariam de modo diferente do que se falasse no lugar do aluno".

\section{Resultados e discussão}

\section{A leitura dos artigos científicos}

Pautamos nosso trabalho na busca de recursos/estratégias capazes de favorecer a capacidade de interpretação do artigo científico pelos alunos. Cabe esclarecer que partimos do princípio de que a leitura desses artigos não deveria ser uma mera decodificação, que costuma ocorrer quando se acredita que o texto tem um sentido e o aluno deve apreender esse sentido (informação).

Temos o mesmo entendimento de Orlandi (2000) a respeito da maneira como se deve encarar o texto e a sua leitura. Segundo a autora, a perspectiva da AD não encara o texto apenas como produto, mas procura observar o processo de sua produção e, logo, da sua

significação. Nesta perspectiva, procuramos estabelecer em sala de aula uma forma de leitura que permitisse ao aluno "trabalhar sua própria história de leitura" (ORLANDI, 2000, p. 37). 
A leitura do artigo científico pelos alunos foi acompanhada da resolução de questionamentos e de posteriores debates a respeito do seu conteúdo e processo de construção. Estes foram elaborados com o objetivo de:

- fomentar a ocorrência de discussões que permitissem a associação de elementos presentes no artigo científico com possíveis fatores (de naturezas variadas) que influenciaram no seu processo de produção. Conforme sugerido por Campanario (2004), o contato com esse tipo de texto pode levar a discussões a respeito dos fatores sociais implícitos em seu conteúdo, e que, muitas vezes, são deixados de lado. Assumimos que questionamentos como os apresentados nas seções B e D (questões 2 a 5, Quadro 1) e na Atividade Extraclasse II (questões 4 e 5, Quadro 2) cumpririam este papel;

- propiciar aos estudantes a aproximação com o conteúdo relativo ao conhecimento químico expresso nos artigos científicos, por meio de questões que visavam o reconhecimento de algumas técnicas de análise e alguns conceitos e substâncias químicas. Reconhecemos que estes questionamentos conduzem para o que Orlandi (2002) chama de leitura no sentido dominante, ou seja, aquela que aponta para o estabelecimento de sentidos únicos ao texto. Estas questões foram inseridas uma vez que acreditamos que, circunstancialmente, quando se está diante de um texto científico, a leitura parafrástica pode ser a mais conveniente. Assim, alguns questionamentos colocados aos alunos não permitem respostas divergentes. Como, por exemplo, quando lhes é solicitada a apresentação dos equipamentos utilizados no procedimento experimental estabelecido no artigo. Questões desta natureza encontram-se nas seções C e D (questão 1, Quadro 1), na Atividade Extraclasse I (questões 1 a 3, Quadro 2) e na Atividade Extraclasse II (questões 1 a 3, Quadro 2).

Algumas questões apresentadas no Quadro 1 e no Quadro 2 destinavam-se, exclusivamente, a contemplar alguns dos objetivos específicos da disciplina onde essa proposta de ensino foi aplicada. Essas questões incentivavam o uso de recursos de buscas bibliográficas nas diversas fontes de informação disponíveis para a área de química.

\section{Os textos produzidos pelos alunos}

$\mathrm{Na}$ análise dos textos, procuramos identificar possíveis elementos que relacionassem a escrita com a interpretação feita pelos alunos do artigo científico. Para a realização desta análise, partimos do seguinte princípio, expresso por Orlandi (1996) no livro Interpretação: para que haja um evento interpretativo é necessário que o sujeito se represente no lugar de autor. Segundo Orlandi, a posição autor se faz na constituição da interpretação, pois o autor não pode dizer coisas que não tenham sentido, o que mostra sua relação com o interdiscurso, e, além de fazer sentido, este deve ser para um interlocutor determinado, que faz parte de suas formações imaginárias. Assim, fizemos a análise dos textos com base no entendimento da noção de autoria apresentada por Orlandi, que, por sua vez, se relaciona com os tipos de repetição formal, empírica e histórica.

$\mathrm{Na}$ análise dos textos produzidos pelos alunos, procuramos identificar em que ocasiões e em que níveis os tipos de repetição estavam presentes. Apresentamos, a seguir, a análise de 5 textos. Acreditamos que os textos escolhidos para a análise refletem a ocorrência dos vários tipos de repetição no conjunto total de 55 textos, e nos permitem desvendar as possibilidades da atividade proposta no que se refere à leitura e interpretação do artigo científico. 
Leitura e interpretação de artigos científicos...

\section{Análise de textos que apresentam predominantemente repetição histórica}

O primeiro texto analisado, produzido pelo aluno denominado de Aluno 1, com base no artigo "Caracterização e classificação do resíduo sólido 'pó balão' gerado na indústria siderúrgica não integrada a carvão vegetal" (OLIVEIRA e MARTINS, 2003), se assemelha ao artigo original no que diz respeito ao objetivo de contextualizar o problema em foco e discutir suas possíveis soluções. Verificamos a articulação de muitas informações relacionadas à justificativa apresentada pelos autores do artigo científico para a realização da pesquisa - o problema da poluição. Embora contenha fragmentos do artigo original, o que poderia indicar a ocorrência de repetição empírica, algumas características do texto sugerem a clara intenção do aluno em se posicionar como sujeito do seu discurso.

Esse aluno adotou uma prática que também foi freqüentemente utilizada em outras produções: na posição de autor, deixou transparecer as necessidades, por ele imaginadas, dos seus leitores, e tratou de atendê-las por meio da inserção, no seu texto, da explicação ou justificativa de alguns conceitos apresentados no artigo científico. Acreditamos que o uso deste artifício esteja relacionado ao funcionamento das formações imaginárias, conforme enunciado por Pêcheux (1997): o aluno lançou mão de uma representação imaginária do seu interlocutor e, com base nela, tratou de estabelecer as suas estratégias discursivas para atingir os seus objetivos. Além disso, ao tomar este cuidado, o aluno define o seu leitor como sendo distinto daquele a quem o artigo científico da área de química se destina. Este último, supostamente, já conhece os conceitos descritos no artigo e não necessita de maiores explicações.

Esta prática pode ser verificada quando analisamos o Fragmento 1, a seguir. Percebemos que o estudante, marcando o seu posicionamento, incluiu, na sua produção, informações que não constavam no artigo científico original, mas que estavam presentes em sua memória, e que parece julgar relevantes para o entendimento do seu discurso por um leitor imaginário. Isto ocorre quando ele faz uso de conhecimento enciclopédico - definição de poluição - como um recurso que traz à tona outras informações.

\section{Fragmento 1}

"O dicionário define poluição como sendo a contaminação ou degradação do meio natural causada por detritos domésticos, industriais e agentes químicos de um modo geral."

Aparentemente, ainda com o intuito de prestar esclarecimento ao seu leitor, conforme ilustra o Fragmento 2, o aluno explicita a importância da pesquisa realizada, fazendo uma associação entre a poluição e as razões pelas quais esta deve ser controlada "[...] a poluição interfere no equilíbrio e na vida dos animais e plantas". O próprio conceito de poluição, que nos é familiar, por si só, confere um "peso" ao que está sendo dito, ou seja, tudo o que já se disse sobre poluição e os seus efeitos estão, de certo modo, significando, funcionando, aí, como a memória discursiva - o interdiscurso - que justifica a relevância da pesquisa.

\section{Fragmento 2}

"Poluição também pode ser definida como a emissão de resíduos sólidos, líquidos ou gasosos em quantidade superior à capacidade de absorção do meio ambiente, maior que a quantidade existente 
Santos, G. R.; Queiroz, S. L.

no meio, ou lançamento de substâncias não naturais. Dessa forma, a poluição interfere no equilí-

brio e na vida dos animais e plantas."

No Fragmento 3, o sujeito explicita também o seu posicionamento, colocando-se como autor, trazendo à tona uma informação de domínio comum, quando se refere às indústrias siderúrgicas "Todos sabemos que [...]", produzindo um lugar de interpretação no meio de outros. Desta forma, também cremos que a construção de um sentido é aí constituída pelo "já-dito", mostrando que este sentido nasceu das possíveis articulações com as suas memórias discursivas em jogo.

\section{Fragmento 3}

"Todos sabemos que as indústrias pesadas são grandes responsáveis pela questão ambiental que enfrentamos."

Ainda nesse texto, identificamos passagens, como a ilustrada no Fragmento 4, nas quais o aluno deixa velada a sua posição em relação ao assunto abordado no artigo científico, ao introduzir uma voz avaliativa, denotando a constituição de um sentido.

\section{Fragmento 4}

"Tentando de alguma forma contribuir contra a poluição, a Universidade Federal de Ouro Preto desenvolveu um estudo sobre este agente poluidor tão importante."

Percebemos, também, a emergência, no texto, de uma abordagem totalmente diferenciada daquela presente no artigo científico, na medida em que o aluno opta por atravessar o seu discurso com analogias (Fragmentos 5 e 6) e intercalação (Fragmento 7), provavelmente visando um melhor entendimento do seu leitor, trazendo para o seu discurso outras leituras articulando outras "vozes" ao texto. Assim, o sujeito mergulha o dizer em sua memória, o significa, elaborando sentidos que lhe permitem formulações outras, em outras situações de linguagem e conhecimento (ORLANDI, 1996).

\section{Fragmento 5}

"Fazendo uma analogia, o pó do balão é como se fosse a areia que é utilizada depois do processo de filtração em uma Estação de Tratamento de Água - esta areia agrega resíduos indesejáveis à água potável."

\section{Fragmento 6}

"Para caracterizar a periculosidade, foi realizado o teste de lixiviação. Análogo ao processo geográfico de lixiviação que, por via da passagem de água, carrega nutrientes do solo para o subsolo."

\section{Fragmento 7}

"Os produtores independentes, no estado mineiro, geram até $45 \mathrm{~kg}$ de Charcok/t gusa (o ferrogusa é o primeiro produto beneficiado numa siderúrgica. É o ferro fundido, em geral, que contém pequenas quantidades de carbureto, siliceto, fosfeto, e sulfeto de ferro e alto teor de carbono; é 
Leitura e interpretação de artigos científicos...

quebradico e, quando submetido a um corte, libera grande quantidade de fagulhas), e a região é

uma das principais do estado."

O segundo texto, produzido no formato de carta pelo aluno denominado aluno 2, com base no trabalho "Separação e identificação de fármacos diuréticos" (VALLADÃO, ZUANON NETTO e IONASHIRO, 1994), chamou atenção por vários elementos apresentados que também dizem respeito ao posicionamento do sujeito. Também fica claro quão diferente são os sentidos produzidos quando se muda o gênero no qual o seu discurso é elaborado (OLIVEIRA, 2001). Na carta produzida pelo aluno, o seu posicionamento se dá no diálogo com o seu interlocutor por meio do uso de frases interrogativas (Fragmento 8). O aluno também prefere iniciar o seu texto articulando-o em torno das atividades desenvolvidas no curso de Química, em especial, da atividade relacionada à leitura do artigo científico (Fragmento 9). O fato de o aluno ter feito referência, em seu texto, ao conjunto de atividades realizadas no curso nos indica que o contexto das situações ocorridas no dia-a-dia do aluno, em sala de aula, influenciou na produção do mesmo, isto é, as práticas realizadas, de algum modo, foram significativas para o aluno, que as incorporou no material escrito.

\section{Fragmento 8}

"Oi mãe. Tudo bem? Como estão as coisas por ai? Aqui está tudo bem, estou tentando me acostumar com a faculdade, mas está difícil."

\section{Fragmento 9}

"Estou te escrevendo pra lhe contar de um trabalho legal que a gente fez na faculdade. Tínhamos que faz̧er uma apresentação oral, e um pôster de um artigo cientifico, o mais legal é que a gente não podia escolher nem o artigo e nem quem iria faz̧er as apresentações."

Ao escrever "o mais legal é que a gente não podia escolher nem o artigo e nem quem iria fazer as apresentações", o sujeito reflete uma postura crítica em relação à atividade, postura que pode ser entendida pelo tom irônico colocado.

No Fragmento 10, o diálogo do sujeito com o seu interlocutor também pode ser evidenciado na antecipação da voz do outro "É mãe, o negócio é sério" e no apelo pela sua atenção, "Bem, vou explicar", "É assim, [...]”. Nos Fragmentos 11 e 12, ocorreu o uso de questionamentos "Sabe o que é isso mãe?", "Não é legal?".

\section{Fragmento 10}

"A amostra do nosso artigo falava sobre fármacos diuréticos. Você também não sabe o que é isso não é? Bem, vou explicar. São remédios que aumentam o fluxo urinário, aqueles que a gente toma pra fazer mais xixi. Eles servem para cuidar de vários tipos de problemas, hipertensão, problemas de próstata etc. Servem até pra perder peso. Só que o uso exagerado pode causar intoxicacãa e até prejudicar os rins. É mãe, o negócio é sério."

\section{Fragmento 11}

"Sabe o que é isso mãe? É um método de análise química, por ele épossivel identificar as substâncias em uma amostra desconhecida." 
Santos, G. R.; Queiroz, S. L.

\section{Fragmento 12}

"[...] e eles concluiram também que todos os remédios continham as substâncias analisadas.

Não é legal?"

O aluno também optou por compor o seu discurso reunindo outras leituras que não estão no artigo original. De modo semelhante ao texto produzido pelo aluno 1, ele achou por bem inserir informações adicionais para o melhor entendimento do seu discurso, para uma aproximação mais efetiva com o seu interlocutor (no caso, a sua mãe), seja pelo resgate de informações relacionadas aos benefícios e malefícios dos fármacos ou pelo acionamento da linguagem popular "[...] aqueles que a gente toma pra fazer mais xixi".

No nosso entender, a repetição histórica ocorreu nesse texto, pois o sujeito produziu certos deslizamentos de sentidos e criou determinados efeitos de comparação que ilustram a assimilação do conteúdo do artigo científico. A forma pela qual esse texto foi criado também nos indica uma despreocupação com as convenções da linguagem usualmente empregada para retratar esse tipo de informação. Isto indica a apropriação do discurso para si, o que é reforçado pela natureza do gênero escolhido para compor o discurso.

Os textos produzidos pelos alunos denominados alunos 3 e 4, baseados no artigo "Separação de ácidos orgânicos do suco de laranja por meio da cromatografia em camada delgada" (SOBU, YAMANKA e ZUANON NETTO, 1995), apresentaram características semelhantes. Chamou-nos a atenção a forma escolhida pelos alunos na composição dos seus discursos. Conforme indicam os Fragmentos 13 a 15, ambos utilizaram características do discurso poético para retratar um tema próprio do discurso científico, pelo menos no que diz respeito ao trabalho com a sonoridade, com os ritmos.

\section{Fragmento 13}

"Sobre uma pesquisa vou lhes contar/ Espero que, em versos, eu possa falar/ É sobre cromatografial Método que permite descobertas até hoje em dia./ Mas isso, o que seria? É a separação dos compostos de uma mistura/ Sendo analisados pela diferença de altura". (Aluno 3)

\section{Fragmento 14}

"Eu vou dizerer/ Você não vai acreditar/ Na importância que há". (Aluno 4)

\section{Fragmento 15}

"Gostarial Ai meu Deus, era tudo que queria". (Aluno 4)

Poderíamos também esperar que os alunos empregassem outras características discursivas previstas para este gênero literário, aquelas nas quais as expressões podem adquirir atribuições reais e irreais, permitindo que uma mesma palavra possa atribuir ou sugerir significados novos. Gregolin (2003), ao discutir a formação de efeitos de sentidos por meio de deslocamentos de gêneros, cita o poema "Lições sobre a água" de Antônio Gedeão. Neste poema o autor relata as propriedades da água e, ao final, nos remete à cena da descrição do suicídio de Ofélia, relatado em Shakespeare (Hamlet). De acordo com a autora, o referido poema pertence ao gênero literário, uma vez que, em sua materialidade discursiva, estão fundidas a forma (poema) e conteúdo (a água, desdobrada do campo das ciências naturais para o 
Leitura e interpretação de artigos científicos...

campo do poético). Este deslocamento se dá no momento em que a água é poetizada por meio da menção ao texto de Shakespeare. Assim, segundo Gregolin (2003, p. 52):

O que é que, no poema 'Lição sobre a água', opera a passagem do discurso científico que enuncia as propriedades genéricas da 'água' ao discurso literário, senão essa remissão a um fundador de discursividade como Shakespeare? Ao enunciar: Foi nesse líquido ... a água já não é mais a água objeto-da-memória-científica, e sim água objeto-da-memória-literária.

Diferentemente do que foi realizado por Gedeão, o conteúdo científico nos textos dos alunos 3 e 4 está, ainda, predominante. Não notamos, nas produções, exemplos que nos sugiram estes tipos de articulações. $\mathrm{O}$ intuito de relatar a pesquisa realizada com o objetivo de satisfazer a proposta inicial da atividade escrita foi mantido.

Conforme verificamos nos Fragmentos 13 e 14, em ambos os textos são encontrados traços de historicização do dizer dos sujeitos, na medida em que trazem o discurso para si "[...] vou thes contar", "Espero que em versos [...]", "Eu vou dizer [...\}", e incorporam de maneira clara, ao seu texto, os conceitos presentes no artigo científico, articulando-os em uma abordagem própria e inteiramente desvinculada da forma e organização do texto original. Desta forma, demonstram destreza com as palavras ao fazerem as devidas correlações entre os termos próprios da linguagem química.

Notamos, também, a preocupação dos alunos em descrever sucintamente a técnica utilizada pelos pesquisadores, oferecendo uma informação básica sobre os seus princípios, evidenciando, novamente, a questão da imagem do outro.

No texto produzido pelo aluno 4 , acreditamos que o sujeito também se mostra presente por meio da reformulação da fala do outro, parodiando a música "Meu erro" da banda "Os Paralamas do Sucesso". Neste caso, o título atribuído pelo aluno à música é "Não tem erro", e o nome da banda é "Pesquisadores de Sucesso". Percebemos, aí, a intenção na construção de sentidos, quando o sujeito adapta a letra da música original com os procedimentos relatados no artigo científico. Provavelmente, o título faz alusão à eficácia do método utilizado, que pode ser comprovada pelos resultados alcançados pelos "Pesquisadores de Sucesso". O efeito de sentidos é claro, o sujeito comporta-se como autor na medida em que diz coisas que têm sentido para um interlocutor determinado (ORLANDI, 1996).

\section{Análise de texto que apresenta predominantemente repetição formal}

O texto produzido pelo aluno denominado aluno 5, com base no artigo "Exposição ocupacional a compostos orgânicos voláteis na indústria naval" (COSTA e COSTA, 2002), é um exemplo de produção onde a paráfrase se destaca. Verificamos, em alguns momentos, a emergência de historicização - não podemos ignorar a tentativa de não reproduzir literalmente os trechos do artigo original e o cuidado para manter a coerência entre os trechos citados. Mesmo assim, textos produzidos desta forma utilizaram recursos do exercício mnemônico e da repetição formal.

O aluno produziu um texto por meio da seleção de trechos provenientes do artigo 
original, conforme percebemos com base na comparação entre os trechos presentes no segundo e no terceiro parágrafos do artigo original e um trecho do texto apresentado pelo aluno:

\section{Segundo e terceiro parágrafos do artigo científico}

"Compostos orgânicos voláteis, como o benzeno, tolueno, xilenos, n-butanol e metilisobutilcetona são comumente encontrados no ar durante o processo de pintura, provenientes da emissão de solventes orgânicos da tinta fresca ou utilizados para dissolver ou dispersar tintas, resinas e produtos de polimentos. Estas substâncias químicas atuam predominantemente sobre o sistema nervoso central como depressoras, e, dependendo da concentração e do tempo de exposição, podem causar desde sonolência, tontura, fadiga até narcose e morte.

$\mathrm{Na}$ indústria naval, a atividade de pintura, exige, na maioria das vezes, um grande número de trabalhadores durante execução dos serviços, devido, não só ao tamanho das peças, como também, à necessidade de se finalizar a tarefa no menor tempo possível e durante a jornada diária de trabalho."

\section{Texto apresentado pelo aluno 5}

"Os principais compostos encontrados foram o benzeno, tolueno, xileno, nbutanol e metilisobutilcetona. Todas estas substâncias químicas atuam no sistema central como depressoras, e, dependendo da concentração das substâncias, podem causar sonolência, tontura, irritação, fadiga e até a morte. E outro agravador do problema é que a atividade de pintura no navio exige um grande número de trabalhadores durante a execução, devido tanto ao porte do navio como também porque se impõe um curto tempo para a realização do trabalho a ser feito. Assim, o grande objetivo desse trabalho foi analisar e quantificar os poluentes em diferentes ambientes deste estaleiro pesquisado."

\section{Considerações sobre os textos que apresentaram predominantemente repetição empírica}

Orlandi (2000) afirma que a repetição empírica é o efeito "papagaio". Na escola, isso se dá quando o aluno repete sem entender, sem formular o que é dito pelo mestre. Em relação aos textos produzidos pelos alunos, percebemos que houve o uso explícito de longos fragmentos apresentados no artigo original. Em alguns casos, a tarefa limitou-se a uma cópia do artigo em questão, isenta de alguns trechos. Isso nos faz sugerir que o aluno, em retorno ao que lhe foi solicitado no final do bimestre letivo, preferiu obter o reconhecimento pela sua atividade apresentando um texto que, provavelmente, carrega em si o que se esperava como resposta. Além de ignorar as diretrizes iniciais para a produção do texto, ou seja, um texto que deveria ser direcionado a um estudante ingressante no curso de química, justifica o raciocínio bastante difundido de que é melhor pecar pelo excesso do que pela falta.

Acreditamos, também, que tal quadro se deva, em parte, à própria imagem que o aluno tem de seu interlocutor, neste caso, o professor. Neste contexto, podemos resgatar o conceito de formação imaginária, anteriormente mencionado na análise do texto do aluno 1. 
Tal crença é de extrema importância para se compreender a razão de o aluno escrever como escreve, uma vez que isto é conseqüência da imagem que o aluno faz da imagem que o professor faz do próprio aluno. Desta forma, não é difícil entender a motivo da incidência de textos que refletiam apenas a reprodução ou o rearranjo, o que demonstra o receio do aluno em assumir o próprio discurso. Vale lembrar que, para esta atividade, foi atribuída uma nota ao texto produzido e que correspondia a trinta por centro da nota da disciplina.

\section{Considerações finais}

A análise dos textos nos permitiu constatar, em quase todos eles, a presença de mais de um tipo de repetição. A maioria dos alunos, após a leitura e discussão dos artigos científicos, conseguiu produzir textos em que a repetição histórica predominou. Nesses casos, percebemos, com freqüência, o desprendimento dos alunos à forma e à ordem como as idéias estavam elaboradas no artigo científico. Este tipo de repetição sinaliza a potencialidade de tais alunos à construção de manifestações próprias com base nos conteúdos apresentados nos artigos, usando uma linguagem mais próxima do seu dia-a-dia, que pode vir a promover a resignificação dos seus conhecimentos. Re-significação esta, por vezes, altamente desejável no Ensino Superior de Química e, constantemente, dificultada pela utilização de estratégias de ensino centradas quase que exclusivamente no professor. De tal forma que este vem desempenhando, ao longo dos anos, o papel de "ensinar coisas e soluções" e, raramente, o de "ensinar ao estudante a aprender coisas e soluções", como sugerem fortemente as Diretrizes Curriculares para os Cursos de Química (ZUCCO, PESSINE e ANDRADE, 1999).

Embora em alguns textos a repetição formal tenha sido constante, e tenhamos observado em poucos textos a predominância da repetição empírica, não acreditamos que estes fatos se constituam em motivos para o desestímulo à idéia de desenvolvimento de trabalhos com artigos científicos nos cursos de graduação em Química. Provavelmente, a aplicação de uma proposta de ensino que ofereça várias atividades de leitura e escrita, ao invés de apenas uma (como a que aqui apresentamos), favoreça, ao longo do tempo, a produção de textos com maior ocorrência de outros tipos de repetição, que não predominantemente a formal e a empírica.

Considerando os resultados alcançados e a importância dos quais estão investidos os atos de interpretação e de repetição histórica, segundo Orlandi (1996) o que produz realmente conhecimento, acreditamos que estratégias de ensino que abarquem um maior leque de atividades e incluam a leitura e discussão de artigos científicos (ou de divulgação científica, por exemplo), além dos conteúdos tradicionalmente abordados nos cursos de graduação em Química, podem trazer para a sala de aula a oportunidade de desenvolvimento de habilidades capazes de levar o aluno a construções de manifestações próprias, a uma posição de autor. Podendo, também, contribuir para que reconheçam a Química como uma construção humana.

Acreditamos que a receptividade da proposta junto aos graduandos foi boa, a julgar pela qualidade e criatividade de muitos dos textos produzidos. Esta constatação contraria a idéia tão difundida de que alunos da área de ciências exatas não gostam de (ou não sabem) escrever, e leva a refletir sobre os benefícios que o incentivo a tarefas de caráter mais subjetivo poderiam trazer para a formação de tais alunos, fomentando qualidades tão importantes como, por exemplo: a capacidade de comunicação, de trabalho em grupo e de pensamento crítico. 
Santos, G. R.; Queiroz, S. L.

A leitura de alguns dos textos produzidos, somados à nossa observação de alguns episódios ocorridos em sala de aula apontam a atividade de leitura e discussão do artigo científico como mediadora para a colocação de posicionamentos que, dificilmente, viriam à tona em aulas tradicionais de Química.

Finalmente, cabe lembrar que o objetivo da atividade não foi avaliar a capacidade de escrita dos alunos, e sim verificar como se dá a interpretação do artigo científico, com base em determinadas atividades de leitura e discussão, elaboradas com o intuito de propiciar reflexões acerca do conteúdo nele exposto e do seu processo de produção. Nesta perspectiva, observamos que, para cada aluno, existem representações distintas na produção do texto escrito sobre o conteúdo do artigo científico. Assim, enquanto alguns alunos se detiveram no comentário de aspectos mais ou menos relacionados ao conteúdo científico, outros se manifestaram a respeito da construção do conhecimento científico ou enfatizaram as atividades realizadas durante o período letivo. As relações estabelecidas são bastante representativas de que cada um relacionou a leitura e as atividades oferecidas às suas noções anteriores, à atenção que o artigo despertou e à necessidade de cumprimento da tarefa.

\section{Referências}

CAMPANARIO, J. M. Algunas posibilidades del artículo de investigación como recurso didáctico orientado a cuestionar ideas inadecuadas sobre la ciencia. Enseñanza de las Ciencias, Barcelona, v. 22, n. 3, p. 365-378, 2004.

COPOLLA, B. P.; EGE, S. N.; LAWTON, R. G. The University of Michigan undergraduate chemistry curriculum 2: instructional strategies and assessment. Journal of Chemical Education, New Rochelle, v. 74, n. 1, p. 84-94, 1997.

COSTA, M. F. B.; COSTA, M. A. F. Exposição ocupacional a compostos orgânicos voláteis na indústria naval. Química Nova, São Paulo, v. 25, n. 3, p. 384-386, 2002.

FOUCAULT, M. A ordem do discurso. São Paulo: Edições Loyola, 2004.

GREGOLIN, M. R. V. Sentido, sujeito e memória: com o que sonha nossa vã autoria? In: ; BARONAS, R. (Orgs.). Análise do discurso: as materialidades do sentido. São Carlos: Clara Luz, 2003. p. 47-58.

OLIVEIRA, O. B. Possibilidades da escrita no avanço do senso comum para o saber científico na $8^{\text {a }}$ série do Ensino Fundamental. 2001. 158f. Dissertação (Mestrado em Educação) - Faculdade de Educação, Universidade de Campinas, Campinas, 2001.

OLIVEIRA, M. R. C.; MARTINS, J. Caracterização e classificação do resíduo sólido "pó balão" gerado na indústria siderúrgica não integrada a carvão vegetal: estudo de um caso na região de Sete Lagoas/MG. Química Nova, São Paulo, v. 26, n. 1, p. 5-9, 2003.

ORLANDI, E. P. Análise de discurso: princípios e procedimentos. Campinas: Pontes, 2002. 
Leitura e interpretação de artigos científicos...

. Discurso e leitura. Campinas: Cortez, 2000.

\section{6.}

. Interpretação: autoria, leituras e efeitos do trabalho simbólico. Petrópolis: Vozes,

PÊCHEUX, M. Análise automática do discurso (AAD-69). In: GADET, F.; HAK, T.

(Orgs.). Por uma análise automática do discurso: uma introdução às obras de Michel

Pêcheux. Campinas: Editora da Unicamp, 1997. p. 61-87.

QUEIROZ, S. L. A linguagem escrita nos cursos de graduação em química. Química Nova, São Paulo, v. 24, n. 1, p. 143-146, 2001.

; ALMEIDA, M. J. P. M. Do fazer ao compreender ciências: reflexões sobre o aprendizado de alunos de iniciação científica em química. Ciência \& Educação, Bauru, v. 10, n. 1, p. 41-53, 2004.

SANTOS, G. R.; SÁ, L. P.; QUEIROZ, S. L. Uso de artigos científicos em uma disciplina de físico-química. Química Nova, São Paulo, v. 29, n. 5, p. 1121-1128, 2006.

SOBU, Y. H.; YAMANKA, H.; ZUANON NETTO, J. Z. Separação de ácidos orgânicos do suco de laranja por meio de cromatografia em camada delgada. Eclética Química, Araraquara, v. 20, p. 95-100, 1995.

VALLADÃO, D. M. S.; ZUANON NETTO, J. Z.; IONASHIRO, M. Separação e identificação de fármacos diuréticos. Eclética Química, Araraquara, v. 19, p. 57-65, 1994.

WHELAN, R. J.; ZARE, R. N. Teaching effective communication in a writing-intensive analytical chemistry course. Journal of Chemical Education, New Rochelle, v. 80, n. 8, p. 904-906, 2003.

ZANON, D. A. V.; ALMEIDA, M. J. P. M.; QUEIROZ, S. L. Contribuições da leitura de um texto de Bruno Latour e Steve Woolgar para a formação de estudantes em um curso superior de química. Revista Electrónica de Enseñanza de las Ciencias, Vigo, v. 6, n. 1, p. 56-69, 2007.

ZUCCO, C.; PESSINE, F. B. T; ANDRADE, J. B. Diretrizes curriculares para os cursos de química. Química Nova, São Paulo, v. 22, n. 3, p. 454-461, 1999. 